\title{
Effect of sustained inflation vs. stepwise PEEP strategy at birth on gas exchange and lung mechanics in preterm lambs
}

\author{
David G. Tingay ${ }^{1-4}$, Risha Bhatia ${ }^{1,3,4}$, Georg M. Schmölzer ${ }^{1,3,5}$, Megan J. Wallace ${ }^{5}$, Valerie A. Zahra ${ }^{5}$ and Peter G. Davis ${ }^{1,3,6}$
}

BACKGROUND: Sustained inflation (SI) at birth facilitates establishment of functional residual capacity (FRC) in the preterm lung, but the ideal lung recruitment strategy is unclear. We have compared the effect of SI and a stepwise positive endexpiratory pressure (PEEP; SEP) strategy in a preterm model.

METHODS: 127 d gestation lambs received either 20-s SI $(n=9)$ or $2 \mathrm{cmH}_{2} \mathrm{O}$ stepwise PEEP increases to $20 \mathrm{cmH}_{2} \mathrm{O}$ every 10 inflations, and then decreases to $6 \mathrm{cmH}_{2} \mathrm{O}(n=10)$. Ventilation continued for $70 \mathrm{~min}$, with surfactant administered at $10 \mathrm{~min}$. Alveolar-arterial oxygen gradient $\left(\mathrm{AaDO}_{2}\right)$, compliance $\left(C_{\text {dyn }}\right.$ ), end-expiratory thoracic volume ( $E E V_{\text {Rp }}$; respiratory inductive plethysmography), and EEV and $C_{d y n}$ in the gravitydependent and nondependent hemithoraces (electrical impedance tomography) were measured throughout. Early mRNA markers of lung injury were analyzed using quantitative real-time PCR.

RESULTS: From 15 min of life, $\mathrm{AaDO} 2$ was lower in SEP group $(P<0.005$; two-way ANOVA). SEP resulted in higher and more homogeneous $C_{\text {dyn }}(P<0.0001)$. Mean (SD) EEV $V_{\text {RIP }}$ at 5 min was $18(9) \mathrm{ml} / \mathrm{kg}$ and 6 (5) $\mathrm{ml} / \mathrm{kg}$ following SEP and SI, respectively $(P=0.021$; Bonferroni posttest); this difference was due to a greater nondependent hemithorax EEV. There was no difference in markers of lung injury.

CONCLUSION: An SEP at birth improved gas exchange, lung mechanics, and EEV, without increasing lung injury, compared to the SI strategy used.

$\mathbf{T}$ he respiratory transition from fetal to ex utero life involves rapidly aerating the fluid-filled lung to establish a functional residual capacity (FRC) (1). In premature infants, this process often requires augmentation with positive pressure ventilation (PPV). How best to apply respiratory support at birth in this population vulnerable to lung and brain injury is unclear and complicated by the rapid changes in lung mechanics during respiratory transition. The initial movement of the air/liquid interface requires a relatively long respiratory system time constant. Once aeration is established, the low compliance state of the surfactant-deficient premature lung results in short time constants.
The role of positive end-expiratory pressure (PEEP) during resuscitation at birth is well established (2-4) and advocated in international resuscitation guidelines (5). If applied adequately, PEEP maintains FRC and reduces lung injury caused by atelectasis (4). More recently, a sustained inflation (SI) at birth, to accommodate the long time constants during liquid to air transition, has been advocated as a strategy for augmenting aeration and FRC $(2,6,7)$ and improving pulmonary and cerebral blood flow (8). In premature rabbits, a SI of $20 \mathrm{~s}$ followed by PPV with PEEP improved FRC (6) compared to PEEP or SI alone. The characteristics of an optimal SI remain unclear. Both pressure and application time influence subsequent aeration during a SI $(6,9)$. An inadequate inflating pressure or duration will not aerate the lung (2), while inappropriate high inflating pressures at birth can cause lung injury $(10,11)$. During resuscitation, clinicians have few tools to guide the administration of a SI, hampering widespread use.

In the already aerated lung, recruitment strategies that target the point of maximum curvature on the deflation limb of the quasistatic pressure-volume relationship (12-14), via gradual stepwise increases and decreases in applied pressure result in greater and more homogenous recruitment, and improved oxygenation, than a SI alone (15). Such strategies generally use oxygenation to define the optimal applied pressure $(13,14,16,17)$, an unreliable parameter at birth (18). Recently, indicators of lung mechanics have been shown to reliably define the point of maximum curvature and optimal pressure in human infants (19), with resultant improvement in compliance, carbon dioxide removal, and oxygenation. Alternatives to SI have not been examined during resuscitation of the newly born premature lung. The existing literature suggests that a stepwise PEEP strategy to aid aeration at birth and achieve lung recruitment may also overcome some of the practical issues of applying an optimal SI $(15,16,19)$.

The aims of this study were to compare the effects of a SI and a stepwise PEEP strategy (SEP) using conventional mechanical ventilation applied at birth on gas exchange, regional and global end-expiratory volume and lung mechanics, and early indicators of lung injury in a preterm lamb model, and to determine

\footnotetext{
'Neonatal Research, Murdoch Childrens Research Institute, Parkville, Australia; ${ }^{2}$ Department of Neonatology, The Royal Children's Hospital, Parkville, Australia; ${ }^{3}$ Neonatal Research, The Royal Women's Hospital, Parkville, Australia; ${ }^{4}$ Department of Paediatrics, University of Melbourne, Melbourne, Australia; ${ }^{5}$ The Ritchie Centre, Monash Institute of Medical Research, Monash University, Clayton, Australia; ${ }^{\circ}$ Department of Obstetrics and Gynaecology, University of Melbourne, Melbourne, Australia. Correspondence: David G. Tingay (david.tingay@rch.org.au) 
the interaction between recruitment maneuver applied at birth and early exogenous surfactant therapy on these outcomes.

\section{RESULTS}

There was no difference in birth weight and cord $\mathrm{pH}$ between the SEP $(n=10)$ and SI $(n=9)$ groups. Combined mean (SD) birth weight was $2.91(0.34) \mathrm{kg}$ and cord $\mathrm{pH} 7.31$ (0.07). All animals completed the study, and there were no pneumothoraces in either group. There were seven female lambs in the SEP group and two in the SI group. Five lambs in SEP were first born compared with eight in SI. Overall, arterial partial pressure of carbon dioxide $\left(\mathrm{PaCO}_{2}\right)$ was kept within target range throughout the study, except at the time of the first arterial blood gas sample at $8 \mathrm{~min}$ in the SI group, where $\mathrm{PaCO}_{2}$ was $62.1(20.0) \mathrm{mmHg}$, and a mean (95\% confidence interval (CI)) $13.1(-0.8,27.1) \mathrm{mmHg}$ greater than SEP at that point (twoway ANOVA with Bonferroni posttest).

Figure 1 shows the positive inflating pressure (PIP), mean airway pressure $\left(P_{\text {aw }}\right)$, pressure amplitude at the airway opening $(\Delta \mathrm{P})$, delivered tidal volume $\left(V_{\mathrm{T}}\right)$, and dynamic compliance $\left(C_{\mathrm{dyn}}\right)$ over the first $180 \mathrm{~s}$ from birth. During the first $20 \mathrm{~s}$, the SEP group mean (SD) PIP was 45.9 (7.3) $\mathrm{cmH}_{2} \mathrm{O}$ compared to the $34.9(1.7) \mathrm{cmH}_{2} \mathrm{O}$ SI $(P<0.01$; two-way ANOVA with Bonferroni posttest). The SEP group $P_{\text {aw }}$ during this period was $21.5(3.0) \mathrm{cmH}_{2} \mathrm{O}$, and a mean $(95 \% \mathrm{CI}) 12.8(7.5,18.0) \mathrm{cmH}_{2} \mathrm{O}$ lower than the SI $P_{\text {aw }}$. Conversely, $P_{\text {aw }}$ was significantly higher in the SEP group between 50 and $120 \mathrm{~s}$, and $170 \mathrm{~s}$ (all $P<0.05$ ). $\Delta \mathrm{P}$ and $V_{\mathrm{T}}$ were significantly lower at 18 and $20 \mathrm{cmH}_{2} \mathrm{O}$, and during the final decremental PEEP steps (all $P<0.05)$. PIP was also significantly lower at the $6 \mathrm{cmH}_{2} \mathrm{O}$ decremental step $(P<$ $0.001)$.

Figure 2a shows the alveolar-arterial oxygen gradient $\left(\mathrm{AaDO}_{2}\right)$ data for both groups. Oxygenation was significantly better from 15 to $70 \mathrm{~min}$ in the SEP group compared to the SI group (all $P<0.05$; Bonferroni posttest), with $\mathrm{AaDO}_{2}$ being mean $(95 \% \mathrm{CI}) 209(46,371) \mathrm{mmHg}$ lower at $70 \mathrm{~min}$ of life.

Figure $\mathbf{2 b}$ shows the global end-expiratory volume from birth $\left(\mathrm{EEV}_{\mathrm{RIP}}\right)$ data. At 5 min of life, the mean (SD) EEV was 6 (5) $\mathrm{ml} / \mathrm{kg}$ compared with 18 (9) $\mathrm{ml} / \mathrm{kg}$ following the SEP $(P=0.021$; two-way ANOVA with Bonferroni posttest). Both groups continued to gain EEV such that statistical differences had disappeared by $8 \mathrm{~min}$ of life.

Required $V_{\mathrm{T}}$ remained constant at $\sim 7 \mathrm{ml} / \mathrm{kg}$ throughout the study in the SEP group but increased with time to a mean (SD) 8.5 (1.4) $\mathrm{ml} / \mathrm{kg}$ by $70 \mathrm{~min}$ in the SI group (Figure 2c) and was statistically significant by $55 \mathrm{~min}(P<0.01$; Bonferroni posttests). $C_{\mathrm{dyn}}$ was greater at all time points in the SEP group (Figure 2d), as was $\Delta \mathrm{P}$ (Figure 2e). Recruitment strategy significantly influenced $C_{\text {dyn }}$ and $\Delta \mathrm{P}$ (both $P<0.0001$; two-way ANOVA). The PEEP that optimized $C_{\mathrm{dyn}}$ in the SEP occurred at $7.9(1.1) \mathrm{cmH}_{2} \mathrm{O}$. After the initial recruitment period, $P_{\text {aw }}$ did not change significantly over time in each group and was higher in the SI group being, overall, a mean (SD) 19.9 (0.5) $\mathrm{cmH}_{2} \mathrm{O}$ compared with $18.3(0.7) \mathrm{cmH}_{2} \mathrm{O}$ in the SEP group $(P<0.001$; Bonferroni posttest $)$.
Prior to surfactant administration, the use of a SI resulted in less homogenous distribution of $C_{\mathrm{dyn}}$ than SEP (Figure 2f). At 8 min of life, the nondependant:dependant (V/D) ratio of relative $C_{\mathrm{dyn}}$ was a mean $(95 \% \mathrm{CI}) 0.25(0.04,0.46)$ higher in the SI group (Bonferroni posttest). Exogenous surfactant administration improved homogeneity of $C_{\mathrm{dyn}}$ in the SI group such that the $\mathrm{V} / \mathrm{D}$ ratio from $45 \mathrm{~min}$ of life was lower compared with $8 \mathrm{~min}(P<0.05$; one-way ANOVA with Tukey posttest). There was no change in the distribution of $C_{\mathrm{dyn}}$ over time in the SEP group.

Overall, SEP resulted in greater recruitment of relative EEV in the nondependent hemithorax (Figure 3a) than SI at all time points. SEP was able to achieve an EEV approximating 1.1 of vital capacity in that region $\left(\Delta Z_{\% \mathrm{VCroi}}\right)$ at all time points, although there was considerable intersubject variability, compared to $0.5 \Delta Z_{\% \text { VCroi }}$ following a SI. This difference was significant prior to surfactant administration $(P<0.05$; two-way ANOVA with Bonferroni posttest). Neither strategy was able to recruit relative EEV close to vital capacity in the dependent lung (Figure 3b). There was no difference in relative EEV following SI in the dependent and nondependent lung. Prior to surfactant administration, EEV in the nondependent lung was significantly higher than in the dependent lung in the SEP group $(P<0.05$; two-way ANOVA with Bonferroni posttest).

\section{Lung Injury}

There was no difference in connective tissue growth factor (CTGF), cysteine-rich 61 (CYR61), early growth response protein 1 (EGR1), and $I L-1 \beta, I L-6$ and $I L-8$ mRNA between the two groups (Table 1).

\section{DISCUSSION}

In our model of the preterm surfactant-deficient lung, the use of a stepwise escalating/deescalating PEEP maneuver with volume-targeted ventilation (VTV) from birth resulted in better oxygenation, lung mechanics, and thoracic volumes, without increasing lung injury, compared with a 20-s SI followed by a similar PPV strategy. This is, to our knowledge, the first study to compare alternative recruitment approaches at birth. Previous studies being limited to strategies using SI and/or PEEP $(2,6)$. Our study demonstrates that a SEP strategy was practical and maybe beneficial in supporting the preterm lung at birth.

The use of PEEP at birth is now widely accepted (5). PEEP maintains FRC and minimizes sheer forces (4), even without a preceding SI (2). The optimum PEEP to apply at birth remains unknown, and identifying it difficult, with detrimental results if inadequate or excessive (4). In our study, we used a PEEP of $6 \mathrm{cmH}_{2} \mathrm{O}$ in the SI group, a clinically relevant value also based on previous literature in the preterm lamb model (20). The SEP group, which used a PEEP defined by the recipient's response rather than the clinician, identified an optimal PEEP that was higher in most subjects. The $2 \mathrm{cmH}_{2} \mathrm{O}$ greater PEEP, rather than the SEP maneuver, may account in part for the differences seen between the two strategies, particularly at a 

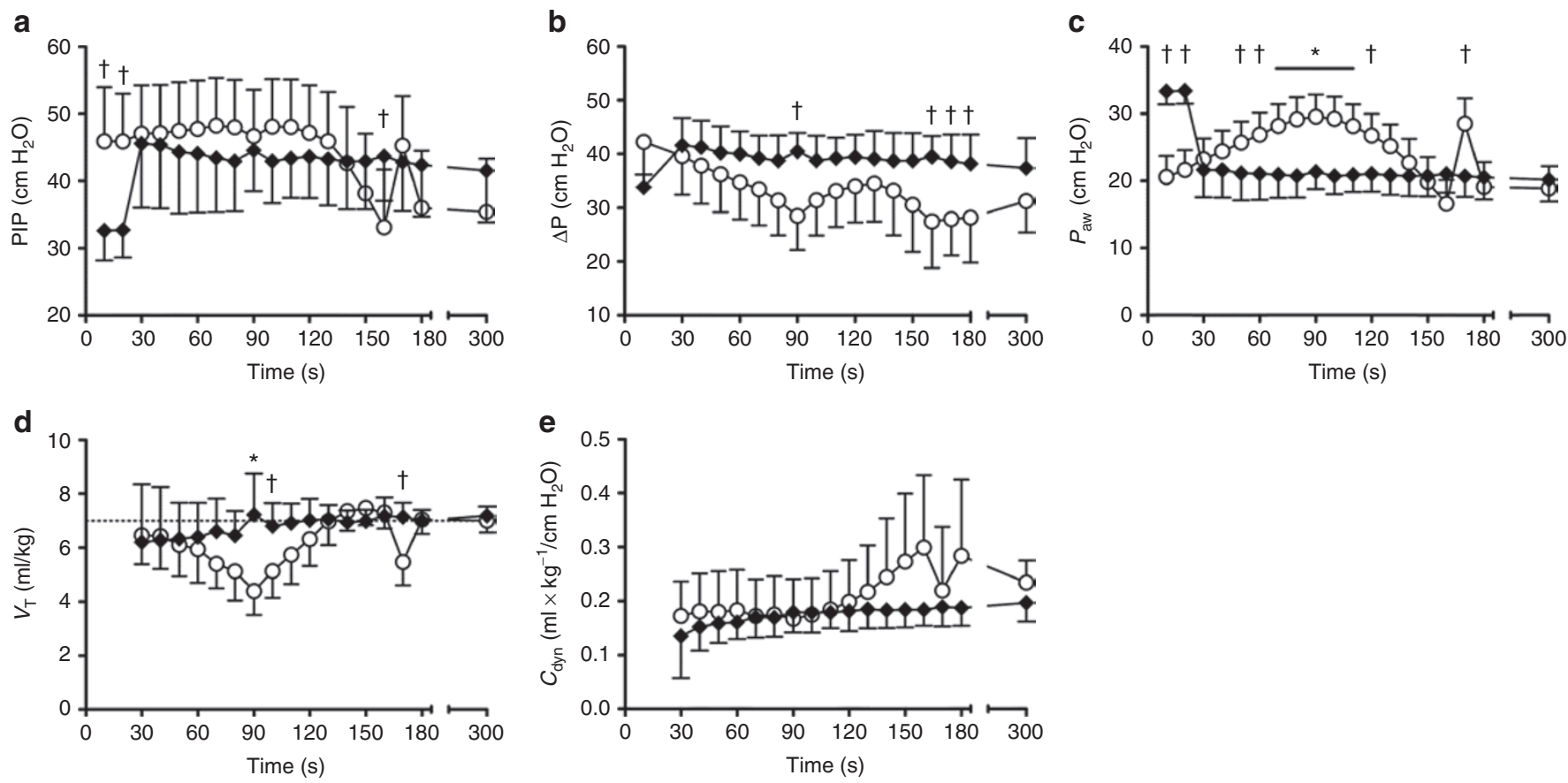

Figure 1. (a) PIP, (b) $\triangle \mathrm{P},(\mathbf{c}) P_{\text {aw' }}$ (d) $V_{\mathrm{T}^{\prime}}$ and $(\mathbf{e}) C_{\mathrm{dyn}}$ for the sustained inflation (closed diamonds) and SEP strategy (open circles) at $10 \mathrm{~s}$ intervals from birth to $180 \mathrm{~s}$, and at $300 \mathrm{~s}$ of life. ${ }^{+} P<0.05$ and ${ }^{*} P<0.0001$ at corresponding time points (two-way ANOVA with Bonferroni posttest). All data are mean $\pm \mathrm{SD}$. $C_{\mathrm{dyn}}$ compliance; $\Delta \mathrm{P}$, airway opening; $P_{\text {aw' }}$ airway pressure; PIP, positive inflating pressure; $V_{\mathrm{T}^{\prime}}$ tidal volume.

a
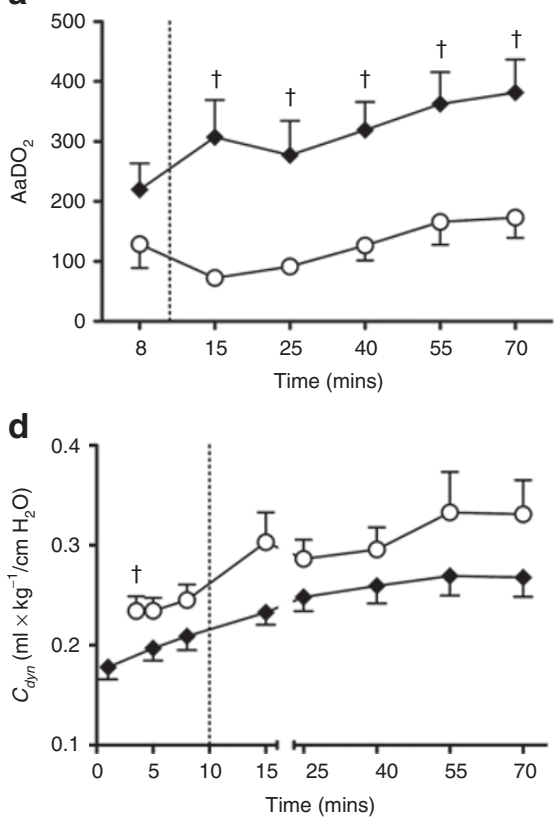

b

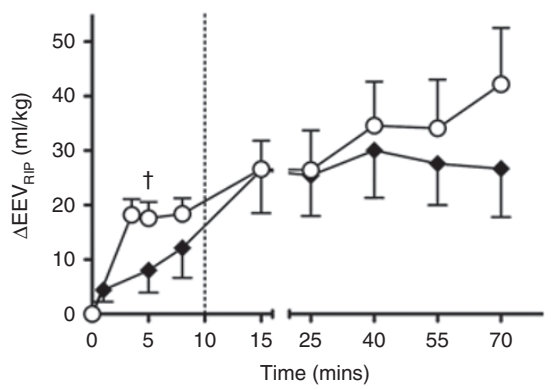

e

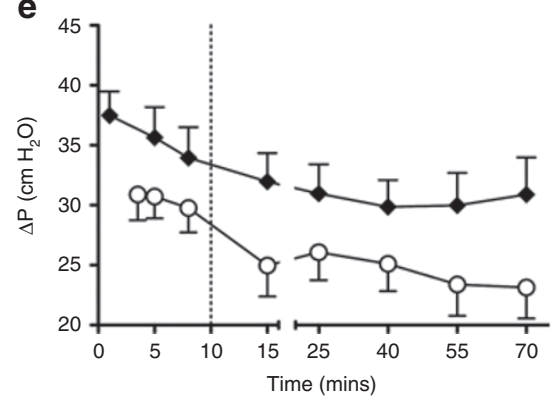

C

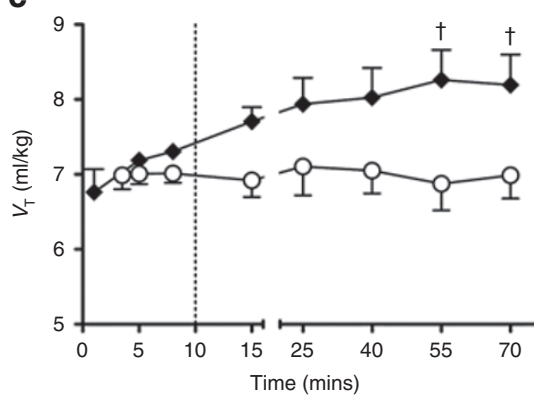

$\mathbf{f}$

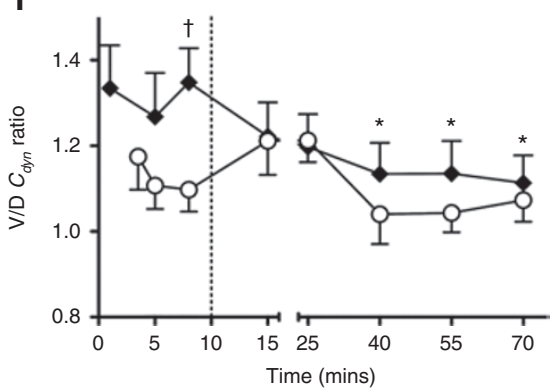

Figure 2. (a) $\mathrm{AaDO}_{2^{\prime}}$ (b) change in $\mathrm{EEV}_{\mathrm{RIP}}(\mathbf{c}) V_{\mathrm{T}^{\prime}}$ (d) $C_{\mathrm{dyn} n^{\prime}}$ (e) $\Delta \mathrm{P}$, and (f) ventral to dorsal hemithorax $C_{\mathrm{dyn}}$ ratio following sustained inflation (closed diamonds) and SEP strategy (open circles) at birth. Exogenous surfactant was administered at $10 \mathrm{~min}$ of life (dashed line). ${ }^{\dagger}$ Indicates a significant difference between data at corresponding time points ( $P$ values $<0.05$, two-way ANOVA with Bonferroni posttest). ${ }^{*}$ Indicates a significant difference between $C_{\text {dyn }}$ ratio at $8 \mathrm{~min}$ of life in the SI group ( $P=0.022$, repeated-measures ANOVA with Tukey posttest). All data are mean $\pm \mathrm{SEM}$. AaDO ${ }_{2}$ alveolar-arterial oxygen gradient; $C_{\mathrm{dyn}}$, compliance; $\mathrm{EEV}$, end-expiratory thoracic volume; $\Delta \mathrm{P}$, airway opening; $V_{\mathrm{T}}$, tidal volume.

regional level, and future studies should compare SI and PPV at various PEEP levels against SEP. Despite this limitation, our findings highlight a clinical advantage of a SEP approach. A SI, due to its relative brevity, provides no direct feedback to the clinician as to subsequent PPV settings. In contrast, a SEP, by virtue of allowing time to evaluate physiological responses $(14,19,21)$, provides clinical information during those critical first few minutes of life. 

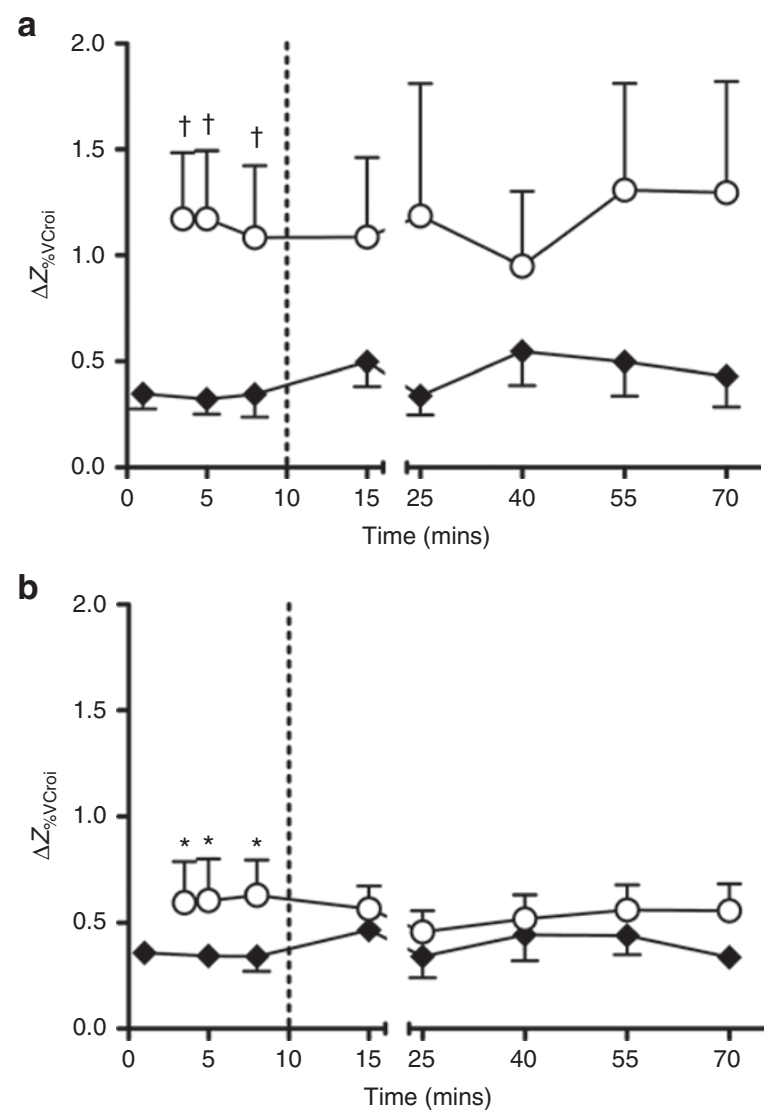

Figure 3. Change in relative end-expiratory thoracic volume $\left(\Delta Z_{\% \text { VCroi }}\right)$ after sustained inflation (diamonds) and SEP strategy (circles) at birth in the nondependent (ventral; a) and dependent (dorsal; b) hemithoraces. Exogenous surfactant was administered at 10 min (dashed line). ${ }^{\dagger}$ Indicates a significant difference between data at corresponding time points ( $P$ values $<0.05$, two-way ANOVA with Bonferroni posttest). * Indicates a significant difference between $Z_{\% \mathrm{~V} \text { croi }}$ in the dependant and nondependant hemithoraces in the SEP group at corresponding time points ( $P$ values $<$ 0.05 , two-way ANOVA with Bonferroni posttest). All data are mean \pm SEM.

The use of an escalating/de-escalating PEEP strategy to recruit the lung and identify an optimal PEEP is not new $(14,17,22)$. In the already aerated lung, these are often called open lung strategies (14), and aim to exploit hysteresis to map the quasistatic pressure-volume relationship of the lung and apply ventilation on the deflation limb at an optimal applied pressure $(13,14)$. Reassuringly, our findings that oxygenation, lung volume, and lung mechanics are improved with this approach, are consistent with previous animal $(23,24)$ and human $(13,16,17)$ studies in aerated diseased lungs. It is on the deflation limb that the most homogenous regional aeration occurs $(13,15)$ and can be maintained with a lower PEEP than needed to recruit the lung $(24,25)$. This, and the longer time allowed for recruitment likely explains the benefits we observed with the SEP compared to the SI.

The use of $C_{\mathrm{dyn}}$ rather than oxygenation as a proxy of lung volume during the SEP strategy differentiates our study from previous open lung reports $(13,19)$. There is a strong rationale for our approach beyond the limitations of peripheral oxygen saturation $\left(\mathrm{Sp}_{\mathrm{O} 2}\right)$ at birth (18). The relationship between lung mechanics and the pressure-volume relationship is well recognized $(12,25)$, and recently, the ability to deliver an SEP using indicators of lung mechanics alone has been described by our group in humans receiving high-frequency oscillatory ventilation (19). This is the first report of a $C_{\mathrm{dyn}}$-defined SEP strategy using conventional PPV. $C_{\mathrm{dyn}}$ and other mechanics parameters are now routinely available on modern ventilators and the use of VTV simplifies the delivery of SEP strategies such that the clinician need only adjusted PEEP. The largest imposition to using complex ventilation strategies in the delivery room environment is the lack of monitoring, despite increasing awareness of importance, and mask/endotracheal tube (ETT) leak (26). The use of modern ventilators, with reliable monitoring and adequate battery supply for transport, in the delivery room is becoming increasingly feasible and may improve resuscitation.

The SEP strategy involved transiently exposing the lung to a PEEP of $20 \mathrm{cmH}_{2} \mathrm{O}$, not a level we advocate in the human infant. Our rationale being that the PEEP required to obtain recruitment in our preterm lung model was unknown. Despite the transient high maximum PEEP and corresponding $P_{\text {aw }}$, the overall $P_{\text {aw }}$ and $\triangle \mathrm{P}$ exposure was lower in the SEP group compared with the SI group, and did not expose the lung to greater pneumothorax risk. Paradoxically, by virtue of the overall greater pressure needs, the SI group may have been at greater risk. It is possible that some subjects did not need a PEEP of $20 \mathrm{cmH}_{2} \mathrm{O}$ to achieve recruitment, thus exposing them to transient overdistension and increased cardiovascular compromise $(8,27)$. The open lung concept advocates a transient rerecruitment after obtaining the minimum PEEP, a PEEP that maybe associated with volume derecruitment. It is possible the transient rerecruitment to $20 \mathrm{cmH}_{2} \mathrm{O}$ was not needed. These may have influenced the results as even brief period of injurious ventilation can initiate injury pathways $(10,28)$. Future studies of SEP at birth should explore titrating both optimal and maximum PEEP to the $C_{\mathrm{dyn}}$ response.

The purpose of a SI at birth is to clear fetal liquid and to allow aeration using sufficient pressure and application time to overcome the high resistance and long time constant of the newly born respiratory system. Without direct imaging, it is impossible to verify whether optimal aeration was achieved in our study. Based on previous literature, $20 \mathrm{~s}$ at a high inflating pressure should be adequate in most subjects $(6,9)$. Whether a longer SI, or the use of higher pressures, would have improved the SI outcome group is unclear. It is unlikely that SI of much longer than $20 \mathrm{~s}$, or pressures above $40 \mathrm{cmH}_{2} \mathrm{O}$, will be accepted clinically at the current time.

During the first $20 \mathrm{~s}$, the PIP was higher in the SEP group than the static $35 \mathrm{cmH}_{2} \mathrm{O}$ SI. This may have exposed the SEP group to higher aerating pressures during the initial phase of lung liquid clearance. The SEP strategy provided 0.4-s dynamic inflations, resulting in a lower $P_{\text {aw }}$ compared to the SI distending pressure during the first $20 \mathrm{~s}$. Previous literature suggests that the distending pressure is more important during aeration and recruitment than tidal PIP $(2,6,20)$. Later, the SEP group was intentionally exposed to a higher $P_{\mathrm{AW}}$ for $80 \mathrm{~s}$; it is possible that this period achieved the subsequent benefits seen in the 
Table 1. Markers of lung injury determined by quantitative real-time PCR

\begin{tabular}{lcccccc}
\hline Strategy & CTGF & CYR61 & EGR1 & IL-1 $\beta$ & IL-6 & IL-8 \\
\hline Sustained inflation & $6.3(1.9)$ & $16.8(15.7)$ & $18.5(24.0)$ & $26.4(16.9)$ & $19.3(9.4)$ & $37.5(16.4)$ \\
SEP & $11.1(9.5)$ & $14.3(9.6)$ & $12.8(8.4)$ & $24.5(16.1)$ & $29.5(24.8)$ & $55.2(24.7)$ \\
\hline
\end{tabular}

mRNA levels are shown as mean (SD) fold increase relative to the levels in an unventilated fetal control group.

SEP groups $(13,16,19)$. Future studies should include a group that receives PPV, with adequate PEEP but no early intentional recruitment maneuver.

\section{Limitations}

There are some additional limitations to our study. Despite randomization, there were differences in gender and parity that may have favored the SEP group. This study used an established lamb model of prematurity. This model is known to require higher pressures than human infants to adequately ventilate the lung. Our lambs were not exposed to antenatal corticosteroids. Whether the same differences would have been present if corticosteroids were administered warrants further investigation. Unlike preterm infants, spontaneous breathing was suppressed in the lambs and cuffed ETT were used, thus translating these findings into human infants should be done with caution. Airway leak remains a major problem with the implementation of any SI, PPV, and SEP strategy at birth. The limitations of electrical impedance tomography (EIT) and respiratory inductive plethysmography (RIP) to measure relative changes in volume have been well described previously $(13,29,30)$ and are relevant to this study. RIP, in particular, is unable to distinguish between fluid and gas within the thorax. Despite these limitations, EIT remains the only validated bedside technique for measuring regional volume with clinical potential in early life (30).

\section{Conclusion}

In a preterm lamb model, the use of a stepwise PEEP strategy during PPV+VTV at birth was practical, tolerated and resulted in better oxygenation, lung mechanics and regional thoracic volume, and lower ventilator settings than a SI. These findings were not associated with increased lung injury and were sustained for at least an hour, highlighting the importance of considering respiratory therapy as a continuum that continues beyond the first critical inflations that achieve aeration. Alternative approaches to supporting the vulnerable preterm lung at birth warrant investigation.

\section{METHODS}

All techniques and procedures were approved by the Animal Ethics Committee of the Murdoch Childrens Research Institute, Melbourne, Australia in accordance with National Health and Medical Research Committee guidelines.

\section{Experimental Instrumentation}

Caesarean section under general anesthesia was performed on datemated ewes at $127-128 \mathrm{~d}$ of gestation (term $\sim 145 \mathrm{~d}$ ). On delivery of the fetal head, the carotid artery and external jugular vein were cannulated. The fetal trachea was intubated with a $4.0 \mathrm{~mm}$ cuffed ETT, and, as per previous reports using this model (8), fetal lung liquid passively drained for $15 \mathrm{~s}$ prior to clamping the ETT. The fetal thorax was then exteriorized and dried. Sixteen custom-built $23 \mathrm{G}, 3 \mathrm{~cm}$ long needle EIT electrodes were placed equidistant around the fetal chest at a level $\sim 0.5 \mathrm{~cm}$ above the xiphisternum. The needles were secured using a $5 \mathrm{~cm}$ wide self-adherent bandage (Coban, $3 \mathrm{M}$, St. Paul, MN), connected to a Goe-MF II EIT system (Carefusion, Hoechberg, Germany), and the quality of the electrode placement confirmed using the EIT proprietary software. Two RIP bands (Respibands, Sensormedics, Yorba Linda, CA) were secured around the chest, one parallel to the upper margin of the Coban bandage and the other immediately above the umbilicus. Following randomization to an assigned protocol, the lamb was delivered, weighed, and ventilated in a supine position.

\section{Measurements}

$\mathrm{Sp}_{\mathrm{O} 2}$, heart rate, arterial blood pressure, and rectal temperature were recorded continuously from birth (HP48S; Hewlett Packard, Andover, MA). Proximal airway pressure $\left(P_{\mathrm{AO}}\right)$ and flow were measured the airway opening using a Florian respiratory mechanics monitor sampling at $200 \mathrm{~Hz}$ (Acutronic Medical Systems, Hirzel, Switzerland). Global lung volume $\left(V_{\text {IRIP }}\right)$ was measured with a DC-coupled RIP (Respitrace 200; NIMS, North Bay Village, FL) (31), sampling at 200 $\mathrm{Hz}$ using a method we have described previously $(13,19)$. The RIP voltage outputs were zeroed to the signal immediately prior to starting ventilation and an uncalibrated change in volume derived from the sum of the chest and abdominal signals. Change in regional volume was measured using EIT sampling at $25 \mathrm{~Hz}(32-34)$.

\section{Ventilation Strategies}

The lambs were randomized to one of the two strategies from birth: (i) an initial SI, via the ETT, of $35 \mathrm{cmH}_{2} \mathrm{O}$ for $20 \mathrm{~s}$ using a Neopuff Infant T-piece Infant Resuscitator (Fisher and Paykel Healthcare, Auckland, New Zealand), followed by $5 \mathrm{~s}$ at a PEEP of $6 \mathrm{cmH}_{2} \mathrm{O}$. The ETT was then clamped to prevent volume loss and PPV (SLE5000; SLE, South Croydon, UK) commenced in VTV mode at a PEEP of $6 \mathrm{cmH}_{2} \mathrm{O}$, inflation time $0.4 \mathrm{~s}, \mathrm{VTV} 7 \mathrm{ml} / \mathrm{kg}$ (maximum PIP $50 \mathrm{cmH}_{2} \mathrm{O}$ ); or (ii) stepwise PEEP strategy (14), using PPV+VTV $(7 \mathrm{ml} / \mathrm{kg}$ and maximum PIP $50 \mathrm{cmH}_{2} \mathrm{O}$ ). Commencing at a PEEP of $4 \mathrm{cmH}_{2} \mathrm{O}$, PEEP was increased by $2 \mathrm{cmH}_{2} \mathrm{O}$ every 10 inflations until a PEEP of 20 $\mathrm{cmH}_{2} \mathrm{O}$ (maximum PEEP setting on ventilator). PEEP was then decreased every 10 inflations to a PEEP of $6 \mathrm{cmH}_{2} \mathrm{O}$. During this process, the $C_{\mathrm{dyn}}$ displayed by the ventilator was observed, and the PEEP that resulted in the highest $C_{\mathrm{dyn}}$ during the decremental phase documented. Then, the lung was rerecruited by transiently exposing the lung to 10 inflations at PEEP $20 \mathrm{cmH}_{2} \mathrm{O}(13,14,16)$, and PPV placed at the PEEP that optimized $C_{\mathrm{dyn}}$. All other PPV+VTV settings were as per SI group.

In both groups, exogenous surfactant (Curosurf $100 \mathrm{mg} / \mathrm{kg}$; Chiesi, Parma, Italy) was administered into the trachea over $30-60 \mathrm{~s}$ at $10 \mathrm{~min}$ of life using an inline premeasured catheter. PPV was initially applied with a fraction of inspired oxygen $\left(\mathrm{F}_{\mathrm{I}} \mathrm{O}_{2}\right)$ of 0.21 in both groups and then titrated to maintain $\mathrm{Sp}_{\mathrm{O} 2}$ of $88-94 \%$. VTV was adjusted to maintain a $\mathrm{PaCO}_{2}$ between 45 and $60 \mathrm{mmHg}$ on arterial blood gas analysis measured at $8,15,25,40,55$, and 70 min of life.

At $70 \mathrm{~min}$ of life, the animals were ventilated with $1.0 \mathrm{FO}$ for $3 \mathrm{~min}$, after which the ETT was disconnected for $2 \mathrm{~min}$ to aid lung collapse. Then, a static in vivo supersyringe pressure-volume curve was performed to a maximum pressure of $40 \mathrm{cmH}_{2} \mathrm{O}$. Lambs were then humanely euthanized with pentobarbitone.

\section{Data Acquisition and Analysis}

$P_{\mathrm{AO}}$, flow, $V_{\mathrm{LRIP}} \mathrm{Sp}_{\mathrm{O} 2}$, heart rate, temperature, and arterial blood pressure were recorded at $1,000 \mathrm{~Hz}$ and digitized using a computerized data acquisition program (Powerlab and LabChart V7; AD Instruments, Sydney, Australia). These parameters and EIT, were 
continuously recorded for the first $15 \mathrm{~min}$ of life, then at $2 \mathrm{~min}$ intervals immediately prior to arterial blood gas analysis, and during the static pressure-volume curve. Data were analyzed continuously during and up to $1 \mathrm{~min}$ after completion of each recruitment maneuver, then the last $30 \mathrm{~s}$ of stable recordings at $5 \mathrm{~min}$ of life, and coinciding with arterial blood gas analysis were used. Applied PIP, PEEP, $P_{\text {aw' }}$ and $\Delta \mathrm{P}$ were determined offline. Delivered $V_{\mathrm{T}}$ and $C_{\mathrm{dyn}}$ were calculated from the flow and $P_{\mathrm{AO}}$ data. The $\mathrm{AaDO}_{2}$ was calculated from the arterial blood gas parameters. Change in $\mathrm{EEV}_{\mathrm{RIP}}$ from birth was determined from the trough of the $V_{\text {LRIP }}$ signal. $V_{\text {LRIP }}^{\text {RIP }}$ voltage signals were calibrated to the known volumes from the static pressure-volume curve using the in-built multipoint linear calibration module in LabChart.

Relative impedance measured by EIT was analyzed offline (AUSPEX V1.6; Carefusion) using our previously described method $(32,35,36)$. The EIT recordings were referenced to the signal immediately prior to ventilation to determine relative change in impedance $(\Delta Z)$ from birth. EEV was then determined from the trough of the impedance signals after applying a low-pass filter at 10 breaths per minute above the second harmonic of the respiratory signal (respiratory domain) $(34,37,38)$. Relative change in EEV from birth was then determined in the nondependant (ventral) and dependant (dorsal) hemithoraces. To allow for intersubject comparison, the EIT data were normalized to vital capacity for each hemithorax. Vital capacity was defined as the impedance change with each hemithorax between 0 and $40 \mathrm{cmH}_{2} \mathrm{O}$ during the static PV curve $\left(Z \%_{V \text { Croi }}\right)(33,36)$.

Relative regional $C_{\mathrm{d}}$ was determined from the EIT signals within the nondependant and dependant hemithoraces using the method described by Dargaville et al. (33). The breath-by-breath tidal amplitude of the impedance signal in each region was determined and divided by the corresponding $\Delta \mathrm{P}$ to determine a regional $C_{\mathrm{dyn}}$ in arbitary units. The $\mathrm{V} / \mathrm{D}$ ratio of relative $C_{\mathrm{dyn}}$ was then determined for each inflation to allow comparison of the homogeneity of relative regional mechanics between subjects. A V/D ratio of 1.0 indicates that the $C_{\mathrm{dyn}}$ is the same in both lung fields, a value $>1.0$ indicates that $C_{\mathrm{dyn}}$ is better in the nondependant lung.

\section{Lung Injury Analysis}

Lung tissue samples were taken from the right lower lobe and immediately frozen in liquid nitrogen for quantitative real-time PCR analysis of early biomarkers of lung injury; CTGF, CYR61, EGR1, IL-1 $\beta, I L$ 6 and $I L-8$ mRNA as described previously (28). Quantitative real-time PCR results were analyzed using the $2^{-\Delta \Delta C T}$ method (28).

\section{Statistical Analysis}

Data were tested for normality and analyzed with a one-way ANOVA or two-way repeated measures ANOVA using time and ventilation strategy as factors and appropriate posttests. Statistical analysis was performed with GraphPad PRISM 4.02 (GraphPad Software, San Diego, CA) and a $P<0.05$ considered significant.

\section{ACKNOWLEDGMENTS}

The authors wish to thank M Sourial and S Osterfield for their assistance in preparation of the ewe and lamb model.

\section{STATEMENT OF FINANCIAL SUPPORT}

This study is supported by a National Health and Medical Research Council Project Grant, Canberra, Australia (Grant ID 1009287) and the Victorian Government Operational Infrastructure Support Program. DGT is supported by a National Health and Medical Research Council Clinical Career Development Fellowship (Grant ID 1053889). PGD is supported by a National Health and Medical Research Council Program Grant (Grant ID 606789) and Practitioner Fellowship (Grant ID 556600).

Disclosure: None.

\section{REFERENCES}

1. Hooper SB, Kitchen MJ, Wallace MJ, et al. Imaging lung aeration and lung liquid clearance at birth. FASEB J 2007;21:3329-37.

2. te Pas $A B$, Siew M, Wallace MJ, et al. Establishing functional residual capacity at birth: the effect of sustained inflation and positive end-expiratory pressure in a preterm rabbit model. Pediatr Res 2009;65:537-41.
3. Siew ML, Te Pas AB, Wallace MJ, et al. Positive end-expiratory pressure enhances development of a functional residual capacity in preterm rabbits ventilated from birth. J Appl Physiol 2009;106:1487-93.

4. Probyn ME, Hooper SB, Dargaville PA, McCallion N, Harding R, Morley CJ. Effects of tidal volume and positive end-expiratory pressure during resuscitation of very premature lambs. Acta Paediatr 2005;94:1764-70.

5. Perlman JM, Wyllie J, Kattwinkel J, et al.; Neonatal Resuscitation Chapter Collaborators. Neonatal resuscitation: 2010 International Consensus on Cardiopulmonary Resuscitation and Emergency Cardiovascular Care Science with Treatment Recommendations. Pediatrics 2010;126:e1319-44.

6. te Pas AB, Siew M, Wallace MJ, et al. Effect of sustained inflation length on establishing functional residual capacity at birth in ventilated premature rabbits. Pediatr Res 2009;66:295-300.

7. te Pas $\mathrm{AB}$, Walther FJ. A randomized, controlled trial of deliveryroom respiratory management in very preterm infants. Pediatrics 2007;120:322-9.

8. Polglase GR, Hooper SB, Gill AW, et al. Cardiovascular and pulmonary consequences of airway recruitment in preterm lambs. J Appl Physiol 2009;106:1347-55.

9. Walsh MC, Carlo WA. Sustained inflation during HFOV improves pulmonary mechanics and oxygenation. J Appl Physiol 1988;65:368-72.

10. Björklund LJ, Ingimarsson J, Curstedt $\mathrm{T}$, et al. Manual ventilation with a few large breaths at birth compromises the therapeutic effect of subsequent surfactant replacement in immature lambs. Pediatr Res 1997;42:348-55.

11. Jobe AH, Kramer BW, Moss TJ, Newnham JP, Ikegami M. Decreased indicators of lung injury with continuous positive expiratory pressure in preterm lambs. Pediatr Res 2002;52:387-92.

12. Goddon S, Fujino Y, Hromi JM, Kacmarek RM. Optimal mean airway pressure during high-frequency oscillation: predicted by the pressurevolume curve. Anesthesiology 2001;94:862-9.

13. Tingay DG, Mills JF, Morley CJ, Pellicano A, Dargaville PA. The deflation limb of the pressure-volume relationship in infants during high-frequency ventilation. Am J Respir Crit Care Med 2006;173:414-20.

14. Lachmann B. Open up the lung and keep the lung open. Intensive Care Med 1992;18:319-21.

15. Pellicano A, Tingay DG, Mills JF, Fasulakis S, Morley CJ, Dargaville PA. Comparison of four methods of lung volume recruitment during high frequency oscillatory ventilation. Intensive Care Med 2009;35:1990-8.

16. De Jaegere A, van Veenendaal MB, Michiels A, van Kaam AH. Lung recruitment using oxygenation during open lung high-frequency ventilation in preterm infants. Am J Respir Crit Care Med 2006;174:639-45.

17. Rimensberger PC, Beghetti M, Hanquinet S, Berner M. First intention high-frequency oscillation with early lung volume optimization improves pulmonary outcome in very low birth weight infants with respiratory distress syndrome. Pediatrics 2000;105:1202-8.

18. Dawson JA, Kamlin CO, Vento M, et al. Defining the reference range for oxygen saturation for infants after birth. Pediatrics 2010;125:e1340-7.

19. Tingay DG, Mills JF, Morley CJ, Pellicano A, Dargaville PA. Indicators of optimal lung volume during high-frequency oscillatory ventilation in infants. Crit Care Med 2013;41:232-9.

20. Sobotka KS, Hooper SB, Allison BJ, et al. An initial sustained inflation improves the respiratory and cardiovascular transition at birth in preterm lambs. Pediatr Res 2011;70:56-60.

21. Miedema M, de Jongh FH, Frerichs I, van Veenendaal MB, van Kaam AH. The effect of airway pressure and oscillation amplitude on ventilation in pre-term infants. Eur Respir J 2012;40:479-84.

22. Froese $\mathrm{AB}$. The incremental application of lung-protective high-frequency oscillatory ventilation. Am J Respir Crit Care Med 2002;166:786-7.

23. van Kaam AH, de Jaegere A, Haitsma JJ, Van Aalderen WM, Kok JH, Lachmann B. Positive pressure ventilation with the open lung concept optimizes gas exchange and reduces ventilator-induced lung injury in newborn piglets. Pediatr Res 2003;53:245-53.

24. Rimensberger PC, Cox PN, Frndova H, Bryan AC. The open lung during small tidal volume ventilation: concepts of recruitment and "optimal" positive end-expiratory pressure. Crit Care Med 1999;27:1946-52.

25. Rimensberger PC, Pache JC, McKerlie C, Frndova H, Cox PN. Lung recruitment and lung volume maintenance: a strategy for improving oxy- 
genation and preventing lung injury during both conventional mechanical ventilation and high-frequency oscillation. Intensive Care Med 2000;26:745-55.

26. Schmölzer GM, Morley CJ, Wong C, et al. Respiratory function monitor guidance of mask ventilation in the delivery room: a feasibility study. J Pediatr 2012;160:377-381.e2.

27. Polglase GR, Morley CJ, Crossley KJ, et al. Positive end-expiratory pressure differentially alters pulmonary hemodynamics and oxygenation in ventilated, very premature lambs. J Appl Physiol 2005;99:1453-61.

28. Wallace MJ, Probyn ME, Zahra VA, et al. Early biomarkers and potential mediators of ventilation-induced lung injury in very preterm lambs. Respir Res 2009;10:19.

29. Wolf GK, Arnold JH. Noninvasive assessment of lung volume: respiratory inductance plethysmography and electrical impedance tomography. Crit Care Med 2005;33:Suppl 3:S163-9.

30. Leonhardt S, Lachmann B. Electrical impedance tomography: the holy grail of ventilation and perfusion monitoring? Intensive Care Med 2012;38:1917-29.

31. Markhorst DG, Jansen JR, van Vught AJ, van Genderingen HR. Breath-tobreath analysis of abdominal and rib cage motion in surfactant-depleted piglets during high-frequency oscillatory ventilation. Intensive Care Med 2005;31:424-30.
32. Tingay DG, Copnell B, Grant CA, Dargaville PA, Dunster KR, Schibler A. The effect of endotracheal suction on regional tidal ventilation and endexpiratory lung volume. Intensive Care Med 2010;36:888-96.

33. Dargaville PA, Rimensberger PC, Frerichs I. Regional tidal ventilation and compliance during a stepwise vital capacity manoeuvre. Intensive Care Med 2010;36:1953-61.

34. Frerichs I, Dargaville PA, van Genderingen H, Morel DR, Rimensberger PC. Lung volume recruitment after surfactant administration modifies spatial distribution of ventilation. Am J Respir Crit Care Med 2006;174:772-9.

35. Bhatia R, Schmölzer GM, Davis PG, Tingay DG. Electrical impedance tomography can rapidly detect small pneumothoraces in surfactantdepleted piglets. Intensive Care Med 2012;38:308-15.

36. Hepponstall JM, Tingay DG, Bhatia R, Loughnan PM, Copnell B. Effect of closed endotracheal tube suction method, catheter size, and post-suction recruitment during high-frequency jet ventilation in an animal model. Pediatr Pulmonol 2012;47:749-56.

37. Armstrong RK, Carlisle HR, Davis PG, Schibler A, Tingay DG. Distribution of tidal ventilation during volume-targeted ventilation is variable and influenced by age in the preterm lung. Intensive Care Med 2011;37:839-46.

38. Carlisle HR, Armstrong RK, Davis PG, Schibler A, Frerichs I, Tingay DG. Regional distribution of blood volume within the preterm infant thorax during synchronised mechanical ventilation. Intensive Care Med 2010;36:2101-8. 